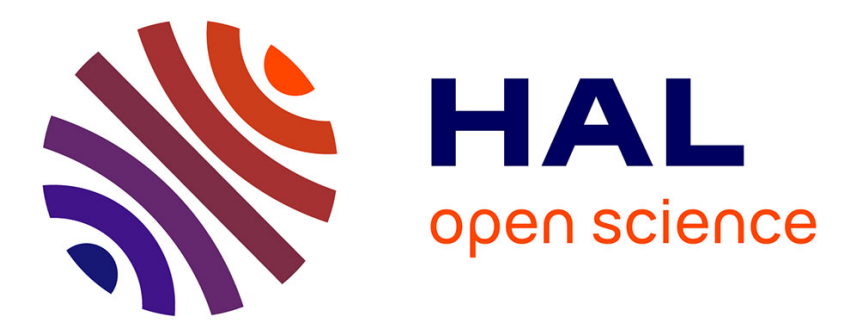

\title{
Photophysical properties of single core multimodal probe for imaging (SCoMPI) in a membrane model and in cells.
}

S. Hostachy, J.-M. Swiecicki, C. Sandt, Nicolas Delsuc, Clotilde Policar

\section{- To cite this version:}

S. Hostachy, J.-M. Swiecicki, C. Sandt, Nicolas Delsuc, Clotilde Policar. Photophysical properties of single core multimodal probe for imaging (SCoMPI) in a membrane model and in cells.. Dalton Transactions, 2016, 45 (4), pp.2791-2795. 10.1093/ecco-jcc/jjw005 hal-01254689

\author{
HAL Id: hal-01254689 \\ https://hal.science/hal-01254689
}

Submitted on 14 Jan 2016

HAL is a multi-disciplinary open access archive for the deposit and dissemination of scientific research documents, whether they are published or not. The documents may come from teaching and research institutions in France or abroad, or from public or private research centers.
L'archive ouverte pluridisciplinaire HAL, est destinée au dépôt et à la diffusion de documents scientifiques de niveau recherche, publiés ou non, émanant des établissements d'enseignement et de recherche français ou étrangers, des laboratoires publics ou privés. 
Photophysical Properties of Single Core Multimodal Probe for Imaging (SCoMPI) in a Membrane Model and in Cells

\section{S. Hostachy, ${ }^{a}$ J.-M. Swiecicki, ${ }^{\text {a C. Sandt, }}{ }^{b}$ N. Delsuc*a and C. Policar*a}

Abstract: The spectroscopic properties of two luminescent Re(I) tricarbonyl complexes conjugated with two cell-penetrating peptides were examined. Fluorescence experiments and IR quantification in membrane models and in cells showed unexpectedly strong luminescence enhancement for one of the complexes in lipid environment.

Metal carbonyl complexes have raised a growing interest as valuable tools for bioimaging. They present strong infrared absorption bands in the IR transparency window of biological media (1800-2200 $\left.\mathrm{cm}^{-1}\right)$, which makes them efficient tags for applications in IR or Raman imaging.1-3 Moreover, with an appropriate ancillary ligand, some of these complexes are luminescent, leading to useful bimodal probes.3 In particular, $\operatorname{Re}(\mathrm{I})$ tricarbonyl complexes incorporating bidentate ligands such as 2,2'bipyridine or pyridinetriazole derivatives (e.g. pyridine-1,2,3-triazole, Pyta) are endowed with interesting photophysical features, such as large Stokes shifts and long luminescence lifetimes.4,5 They also show low toxicity and are stable in biological media. Our group recently demonstrated the possible application of such complexes as bimodal probes for correlative studies involving the detection of the probes by both infrared and luminescence microscopies.3,6 These Single Core Multimodal Probes for Imaging (SCoMPI) were for instance used for labelling and bimodal imaging of biomolecules such as an estrogen derivative 7 or peptides. 8 In addition, the IR modality of SCoMPI allowed to reliably quantify the labelled molecules in biological media, which is not straightforward using fluorescence microscopy as the quantum yields are highly dependant on the environment.9 A recent study showed that accumulation in membranes of fluorescently labelled cell-penetrating peptides (CPP) lead to selfquenching of the label in the case of most of commonly used fluorescent dyes (fluorescein and rhodamine).10 The authors highlighted that this phenomenon could potentially introduce a bias in the interpretation of their location in bioimaging studies by hampering the visualization of cells regions where the labelled CPPs are highly concentrated.
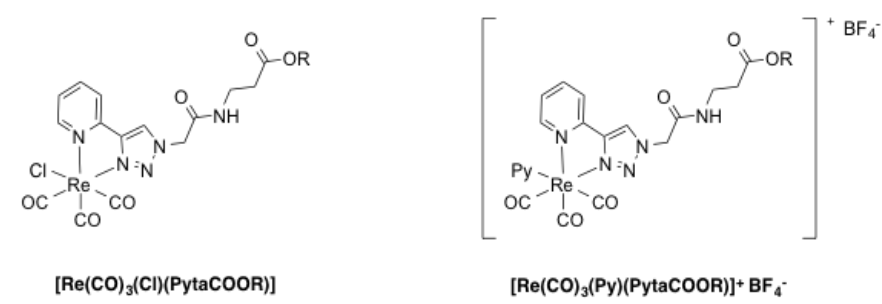

Fig. 1 Structures of the Re(I) tricarbonyl complexes $(\mathrm{R}=\mathrm{Me}, \mathrm{H})$

Modifying the rhenium coordination sphere has an impact on its spectroscopic properties8,11-16 and our group recently investigated the effects of structural modifications of the bidentate ligand on the luminescence properties of $\operatorname{Re}(\mathrm{I})$ tricarbonyl complexes.17 In the present work, we focused on the effect of the monodentate ancillary ligand (chloride or pyridine) on the spectroscopic and physicochemical properties of the SCoMPI. 
The photophysical properties of a luminophore may be altered by its environment and local concentration. In order to test the behaviour of the $\operatorname{Re}(\mathrm{I})$ tricarbonyl probes in membranes, we thus designed two Re(I) tricarbonyl complexes (Fig. 1) suitable for Nterminus labelling of peptides, grafted them to two CPP (namely R9 and R6W3)18,19 and compared their luminescence and physico-chemical properties in solution or in presence of lipid model membranes. The halide ligands are potentially more readily exchanged than the pyridine; besides, it should be noted that the positive charge of the $\left[\operatorname{Re}(\mathrm{CO})_{3}(\right.$ Pyta $\left.)(\mathrm{Py})\right]+$ complex may have an impact on the properties of the probe, including interactions with membranes.

The 4-(2-pyridyl)-1H-1,2,3-triazole ligand (Pyta-COOMe) 3 was easily obtained in three steps and in good yield starting from chloroacetyl chloride. Reaction of chloroacetyl chloride with $\beta$-alanine methyl ester hydrochloride salt in dry DCM lead to the chloride derivative 1 (Scheme 1). The nucleophilic substitution of the chloride by an azido group, followed by a cycloaddition with 2-ethynylpyridine according to standard CuAAC procedures, led to the Pyta ligand 3. The ligand was then refluxed in toluene in presence of the rhenium precursor $\operatorname{Re}(\mathrm{CO})_{5} \mathrm{X}(\mathrm{X}=\mathrm{Cl}, \mathrm{Br})$, leading to the formation and precipitation of $\left[\mathrm{Re}(\mathrm{CO})_{3}(\mathrm{X})\right.$ (PytaCOOMe)] complexes $(\mathrm{X}=\mathrm{Cl}, \mathrm{Br})$. The chloride derivative 4 was then saponified by lithium hydroxide in a mixture of THF and water $(2: 1, v: v)$ to obtain 5 . Although undesired exchange of the chloride ligand with carboxylates has been described for rhenium tricarbonyl chloride complexes,20 in our hands this exchange did not occur during saponification. This might be due to different experimental conditions (temperature, base, reaction time). For the $\operatorname{Re}(\mathrm{I})$ bromide complex, on the other hand, ligand exchange was performed using the protected form of the complex. We chose bromide as precursor for the ligand exchange with pyridine, since bromide is more labile than chloride. This bromide derivative of the complex 6 was refluxed in acetonitrile in presence of silver tetrafluoroborate, then in THF in presence of an excess of pyridine, to obtain the protected form of the rhenium tricarbonyl pyridine complex 7 in good yields. Saponification was then performed on the complex to obtain compound 8. In both synthetic pathways, the complexes were obtained as a racemic mixture of fac isomers. Due to the harshness of conditions for the peptide cleavage from the resin, labelling of R9 and R6W3 with the rhenium complexes was not successful on solid support and was performed in solution. To do so, the complex was first activated with either EDC or DCC/NHS, and then reacted with the desired peptide. The reaction mixture was then directly purified by HPLC. Particular attention was paid to the chloride derivative, as we could observe in some cases a slow chloride exchange under HPLC conditions involving $0.1 \%$ of trifluoroacetic acid. In order to avoid this exchange, the labelled peptide solutions were freeze-dried immediately after purification. 


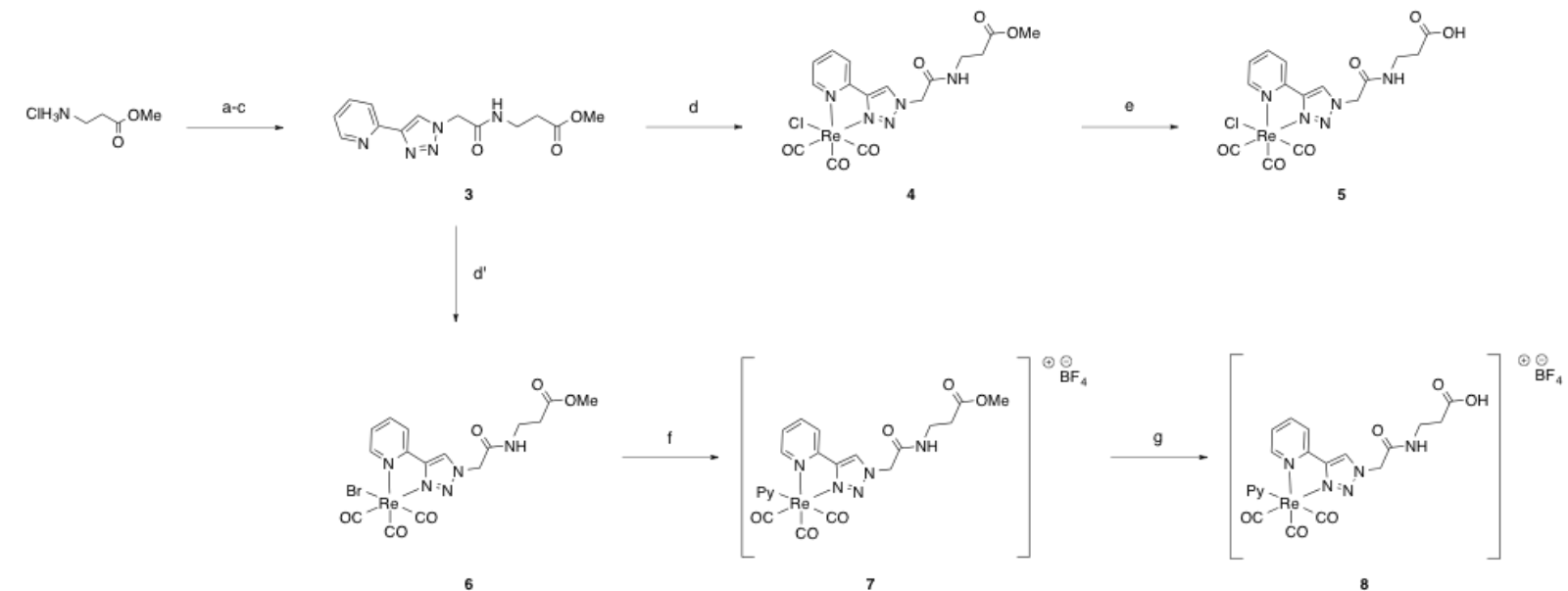

Scheme 1. Synthesis of the SCoMPI derivatives. Reaction conditions : (a) chloroacetyl chloride, DIEA, dry DCM, $1 \mathrm{~h}, 0^{\circ} \mathrm{C}$ to $\mathrm{RT}, 66 \%$, (b) $\mathrm{NaN}_{3}, \mathrm{NaI}$, acetone/water $(3: 1 \mathrm{v}: \mathrm{v}), 16 \mathrm{~h}, 35^{\circ} \mathrm{C}, 79 \%$, (c) 2-ethynylpyridine, $\mathrm{CuSO}_{4}$, sodium ascorbate, acetone/water (2:1 v:v), 2h, RT, 70\%, (d) $\operatorname{Re}(\mathrm{CO})_{5} \mathrm{Cl}$, toluene, 6h, reflux, $100 \%$, (d') $\mathrm{Re}(\mathrm{CO})_{5} \mathrm{Br}$, toluene, 6h, reflux, $100 \%$, (e) $\mathrm{LiOH} \cdot \mathrm{H}_{2} \mathrm{O}$, THF $/ \mathrm{H}_{2} \mathrm{O}$ (2:1 v:v), $45 \mathrm{~min}$., RT, $80 \%$, (f) i. AgBF 4 , acetonitrile, 5h, reflux, Ar; ii. pyridine, THF, 20h, reflux, 79\%, (g) $\mathrm{LiOH} \cdot \mathrm{H}_{2} \mathrm{O}$, THF $/ \mathrm{H}_{2} \mathrm{O}(2: 1 \mathrm{v}: \mathrm{v}), 45 \mathrm{~min} ., \mathrm{RT}$, $87 \%$.

We focused on the spectroscopic properties of the Re(I) probes 6 and 7 in solution. We recorded the absorption and emission spectra of $10 \mu \mathrm{M}$ solutions in water containing 2\% DMSO. Absorption spectra of both complexes showed a shoulder around $335 \mathrm{~nm}$ with typical MLCT features. Excitation of the MLCT band at $350 \mathrm{~nm}$ led to a broad emission band centered around $525 \mathrm{~nm}$ or $495 \mathrm{~nm}$ for bromide (6) and pyridine (7) derivatives, respectively. Moreover, emission intensity was much higher in the case of the pyridine derivative than in the case of the bromide derivative. Indeed, the pyridine derivative displays a higher quantum yield in solution (Table S1, SI).

We further studied the properties of the rhenium complexes grafted to peptides $\mathrm{R} 9$ and R6W3 (Fig S1). Upon conjugation with each peptide, the position $\lambda_{\max }$ of maximal emission intensity for excitation at $350 \mathrm{~nm}$ is retained in the case of the pyridine complex, whereas it is red shifted for the chloride counterpart. In addition, the peptides labelled with the rhenium tricarbonyl pyridine complex display higher emission intensities than those labelled with the chloride derivative. The difference in quantum yields between the chloride and the pyridine form is smaller for all the labelled peptides than for the free probes ( 4 and 7). Besides, when the probe is the rhenium pyridine complex, emission intensity of Py-R9 is about four times higher than that of Py-R6W3, possessing three tryptophan residues. Such intensity quenching might be due to photoinduced electron transfer from the rhenium complex to tryptophan(s). Indeed, examples of such electron transfer have already been reported in the literature. 21 

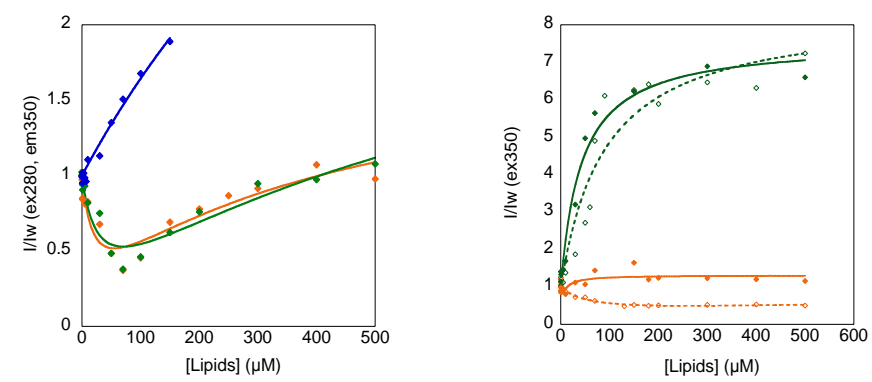

Fig. 2 Evolution of fluorescence emission of tryptophan (left) and SCoMPIs (right) with lipid concentration. Peptide concentration was set at $1 \mu \mathrm{M}$ in PBS buffer (100 mM, pH 7.4) Py-R9, orange, dashed line; Py-R6W3, orange, solid line; Cl-R9, green, dashed line; Cl-R6W3, green, solid line; Ac-R6W3, blue, solid line.

As mentioned above, the complex bearing a pyridine ligand is positively charged, whereas its chloride counterpart is not. We consequently evaluated the influence of this additional charge - and of the SCoMPI itself - on the interaction of a labelled CPP with membranes. Tryptophan fluorescence is often used to sense the local environment of peptides and proteins and to study their interaction with model membranes.22 We examined the evolution of tryptophan emission for three peptides (Cl-R6W3, Py-R6W3 and Ac-R6W3 as a control) in solution and in presence of various concentrations of DOPG vesicles, an anionic phospholipid (Fig. 2 left). In solution and upon excitation of tryptophan at $280 \mathrm{~nm}$, Ac-R6W3 displays the expected broad emission band at $355 \mathrm{~nm}$. Both Py-R6W3 and Cl-R6W3 also exhibit this band, but with a much weaker intensity. Since the emission of tryptophan corresponds to excitation of the MLCT band of the rhenium complexes, this decrease could be due to some energy transfer to the rhenium label since a band at $530 \mathrm{~nm}$ is also observed. In presence of DOPG vesicles, the emission maxima were blue-shifted for all peptides as the lipid concentration increased (from 355 to $335 \mathrm{~nm}$ ), which could be attributed to a rigid environment around the peptide.21 At low lipid concentrations, the maximal emission intensity of Ac-R6W3 showed little (if any) decrease, before increasing at higher lipid concentrations. On the contrary, for both Cl-R6W3 and Py-R6W3, typical self-quenching profiles could be observed, as described by Castanho et al,22 with a decrease followed by an increase of the tryptophan emission intensity at $350 \mathrm{~nm}$ as the lipid:peptide ratio increased. In addition, the emission intensity due to rhenium complex $(\lambda \max =495 \mathrm{~nm}$ or $520 \mathrm{~nm}, \lambda \mathrm{ex}=280 \mathrm{~nm})$ increased with lipid concentration which possibly results from Förster resonance energy transfer. Fitting of these data using simple partition and self-quenching models led to an estimation of partition coefficient of the three peptides between membrane and solution (Table S2, SI). All $\mathrm{K}_{\mathrm{P}}$, although not identical, were of the same order of magnitude. Conjugation of the peptide with SCoMPI thus did not affect significantly its interaction with membrane.

We also investigated the evolution of luminescence of the rhenium complexes in presence of DOPG vesicles, (Fig. 2 right) upon irradiation in the MLCT band. For peptides labelled with the probe bearing the pyridine ligand $\left[\operatorname{Re}(\mathrm{CO})_{3}(\mathrm{Pyta})(\mathrm{Py})\right]+$, the emission intensity showed little variation (Py-R6W3) or a 2-fold decrease (Py-R9) and reached a plateau at high lipid:peptide ratios. A slight blue shift was observed upon addition of hydrophobic vesicles, which is consistent with what was observed with the unconjugated probe in solvents of different polarity: the emission maximum of compound 7 is red shifted in less hydrophobic solvents (acetonitrile, methanol) as compared with water (Fig S2). On the other hand, the peptides labelled with the probe 
bearing the chloride ligand $\left[\operatorname{Re}(\mathrm{CO})_{3}(\mathrm{Pyta})(\mathrm{Cl})\right]$ displayed important fluorescence enhancement at high lipid:peptide ratio (i.e. when most of the peptides are bound to the membrane). The emission maximum is blue-shifted from $550 \mathrm{~nm}$ to $520 \mathrm{~nm}$ at very low lipid:peptide ratio, then slightly red-shifted to $527 \mathrm{~nm}$ at high lipid:peptide ratios. At low lipid concentration, the emission maximum of $\mathrm{Cl}-\mathrm{R} 9$ and Cl-R6W3 is similar to that of the unconjugated probe (compound 4) in aqueous solution (Fig. S2). The initial blue-shift may thus be due to the shielding of the interaction between the peptide and the probe in the lipidic environment.9 When the lipid:peptide ratio is increased, the labelled peptide dilutes in the membrane, which corresponds to a less polar environment. This is consistent with the red shift and hyperchromic effect (for both peptides, emission intensity in lipid environment was more than five times higher than in aqueous solution) of the unconjugated probe in organic solvents with decreasing polarity (in the order water, methanol, acetonitrile) (Fig S2).9 This suggests that in presence of hydrophobic vesicles, the probe is protected from solvent quenching and thus in close contact with the membrane. Despite its lower quantum yield in aqueous solution, the chloride derivative is thus more likely to be detected in lipid environments such as cell membranes, unlike common organic fluorophores that may quench when they accumulate in membranes.
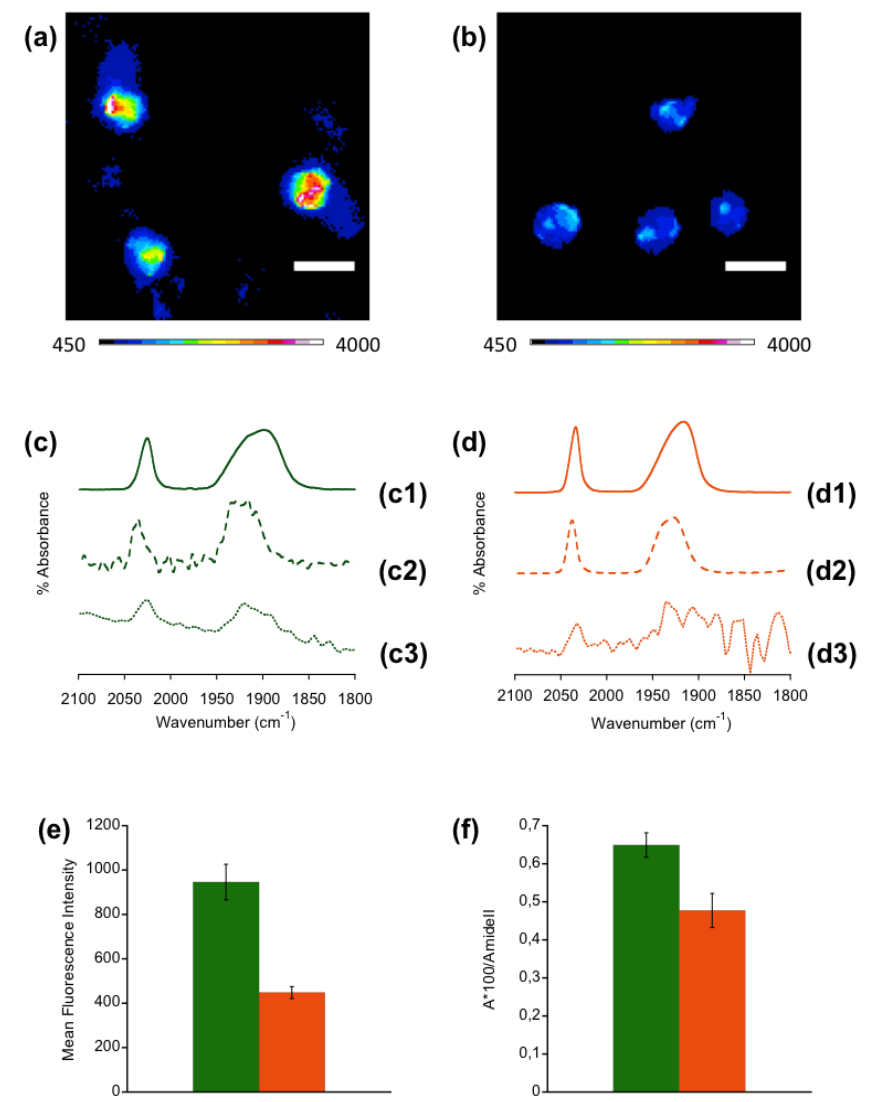

Fig. 3 Comparison of Fluorescence and Infrared Signals of CHO cells incubated with SCoMPI-labelled R9. (a,b) CHO cells incubated for $1 \mathrm{~h}$ at $37{ }^{\circ} \mathrm{C}$ with $10 \mu \mathrm{M}$ Cl-R9 (a) or Py-R9 (b). Intensity scales were set identical for both images, and vary from black/blue (low intensity) to red/white (high intensity). Scale bars $=20 \mu \mathrm{m}$. (c) Infrared absorbance signal of SCoMPI-Cl: (c1) pure compound 4, (c2) pure Cl-R9 in PBS, (c3) Cl-R9 in CHO cells: A -band $\left(2025 \mathrm{~cm}^{-1}\right)$ and E-band $\left(1900 \mathrm{~cm}^{-1}\right)$; (d) Infrared absorbance signal of SCoMPI-Py: (d1) pure compound 7, (d2) pure Py-R9 in PBS, (c3) Py-R9 in CHO cells: A 1 -band $\left(2035 \mathrm{~cm}^{-1}\right)$ and E-band (1940 $\mathrm{cm}^{-1}$ ); (e) Mean fluorescence intensities measured on regions of interest (ROI) for CHO cells incubated with Cl-R9 (green, $n=47$ ROI) or Py-R9 (orange, $n=41$ ROI). (f) Mean Area of A1-band of SCoMPI for CHO cells incubated with Cl-R9 (green, $n=33$ spectra) or Py-R9 (orange, $n=13$ spectra). Error bars represent standard error of the mean. 
We wanted to further confirm these results in a more biologically relevant environment. We incubated Chinese Hamster Ovarian (CHO) cells with SCoMPI-labelled nona-arginine peptides Py-R9 or Cl-R9, and compared the fluorescence intensities displayed in both samples. We could observe heterogenous labelling of CHO cells in both cases. However, as can be seen from Fig. 3a, b and c, mean fluorescence intensity for cells incubated with Cl-R9 was approximately twice the one of Py-R9. In order to verify that this discrepancy was not due to differences in concentration, we then performed infrared measurements on the same samples. As already mentioned, unlike fluorescence intensity, areas of infrared signals are not much dependant on the environment, 9 which was previously verified in the case of Re(I) tricarbonyl. Infrared signals can thus be reliably used for quantification. A1-band of SCoMPI was already used in previous studies for quantification purposes, $2,6,8,9$ and we integrated this band in order to compare the amounts of SCoMPI-labelled peptides in cells (Fig. 3c,d). We recorded infrared spectra on each sample with a $50 \times 50 \mu \mathrm{m}^{2}$ resolution. Given this relatively low resolution, we could not record infrared spectra at the single cell levels. The signals was integrated in a given area comprising several cells. We thus normalized the measured areas of A1-band by the area of Amide II band, which is related to the amount of proteins, and thus to the number of cells. Contrarily to what could be observed for fluorescence, the infrared signal of SCoMPI was almost the same for both samples (Fig. 3f). Although the amount of Py-R9 is slightly lower than Cl-R9, the difference was not as high as the one observed for fluorescence. It can thus be concluded that both SCoMPI-labelled peptides are present in comparable concentrations in both samples, but display very different fluorescence intensities. The behaviour of both SCoMPIs highlighted by experiments on model membranes was thus confirmed in cells.

In this work, we designed and synthesized two rhenium tricarbonyl complexes that possess different ancillary ligands (pyridine or chloride) and are suitable for peptide labelling. We then tested their photophysical and physico-chemical properties in solution and when grafted onto peptides that can be inserted in lipid model membranes. In aqueous solution, the probe with the pyridine ligand possesses a higher quantum yield and a better stability. In membrane model, depending on the nature of the ancillary ligand, the behaviours of the probes are totally different. When the ligand is a pyridine, only small variation in emission intensity was observed when bound to membranes. Contrarily, emission intensity of the rhenium tricarbonyl chloride derivatives increased remarkably (at least 5 times) when bound to membranes, which was confirmed in cells. Despite more modest spectroscopic properties in solution, the SCoMPI bearing a chloride ligand proved to be a better choice than its pyridine counterpart for detection of peptides or other biomolecules in a membrane environment.

\section{Acknowledgements}

Dr Z.Gueroui is gratefully acknowledged for access to fluorescence microscopy facilities. We are also grateful to F.Illien for cell culture. We acknowledge SOLEIL for providing access to its infrared microscopy facility and we would like to thank the SMIS beamline staff for its kind assistance. ENS, CNRS and UPMC-Paris 6 are acknowledged for financial support and ENS for SH's PhD fellowship.

\section{Notes and references}

1 K. Meister, J. Niesel, U. Schatzschneider, N. Metzler-Nolte, D. A. Schmidt and M. Havenith, Angew. Chem. Int. Ed., 2010, 49, 3310. 
2 C. Policar, J. B. Waern, M.-A. Plamont, S. Clède, C. Mayet, R. Prazeres, J.-M. Ortega, A. Vessières and A. Dazzi, Angew. Chem. Int. Ed., 2011, 50, 860.

3 S. Clède and C. Policar, Chem. - Eur. J., 2015, 21, 942-958.

$4 \quad$ K. K.-W. Lo, K. Y. Zhang and S. P.-Y. Li, Eur. J. Inorg. Chem., 2011, 2011, 3551.

5 A. J. Amoroso, M. P. Coogan, J. E. Dunne, V. Fernández-Moreira, J. B. Hess, A. J. Hayes, D. Lloyd, C. Millet, S. J. A. Pope and C. Williams, Chem. Commun., 2007, 3066.

6 S. Clède, F. Lambert, C. Sandt, Z. Gueroui, M. Réfrégiers, M.-A. Plamont, P. Dumas, A. Vessières and C. Policar, Chem. Commun., 2012, 48, 7729.

$7 \quad$ S. Clède, F. Lambert, C. Sandt, S. Kascakova, M. Unger, E. Harté, M.-A. Plamont, R. Saint-Fort, A. Deniset-Besseau, Z. Gueroui, C. Hirschmugl, S. Lecomte, A. Dazzi, A. Vessières and C. Policar, Analyst, 2013, 138, 5627.

8 S. Clède, N. Delsuc, C. Laugel, F. Lambert, C. Sandt, A. Baillet-Guffroy and C. Policar, Chem. Commun., 2015, 51, 2687.

9 S. Clède, F. Lambert, R. Saint-Fort, M.-A. Plamont, H. Bertrand, A. Vessières and C. Policar, Chem. - Eur. J., 2014, 8714.

10 J.-M Swiecicki, F. Thiebaut, M. Di Pisa, S. Gourdin, J. Tailhades, C. Mansuy, F. Burlina, S. Chwetzoff, G. Trugnan, G. Chassaing and S. Lavielle, How to unveil self quenched fluorophores and subsequently map the subcellular distribution of exogenous peptides, unpublished results. b) R. I. MacDonald, J Biol. Chem., 1990, 265, 13533. c) L. W. Runnels, S. F. Scarlata, Biophys. J., 1995, 69, 1569.

11 M. Wolff, L. Munoz, A. François, C. Carrayon, A. Seridi, N. Saffon, C. Picard, B. Machura and E. Benoist, Dalton Trans., 2013, 42, 7019.

12 A. Seridi, M. Wolff, A. Boulay, N. Saffon, Y. Coulais, C. Picard, B. Machura and E. Benoist, Inorg. Chem. Commun., 2011, 14, 238.

13 M. Obata, A. Kitamura, A. Mori, C. Kameyama, J. A. Czaplewska, R. Tanaka, I. Kinoshita, T. Kusumoto, H. Hashimoto, M. Harada, Y. Mikata, T. Funabiki and S. Yano, Dalton Trans., 2008, 3292.

14 T. Y. Kim, A. B. S. Elliott, K. J. Shaffer, C. John McAdam, K. C. Gordon and J. D. Crowley, Polyhedron, 2013, 52, 1391.

15 R. Huang, G. Langille, R. K. Gill, C. M. J. Li, Y. Mikata, M. Q. Wong, D. T. Yapp and T. Storr, JBIC J. Biol. Inorg. Chem., 2013, 18, 831.

16 T. U. Connell, D. J. Hayne, U. Ackermann, H. J. Tochon-Danguy, J. M. White and P. S. Donnelly, J. Label. Compd. Radiopharm., 2014, 57, 262.

17 H. C. Bertrand, S. Clède, R. Guillot, F. Lambert and C. Policar, Inorg. Chem., 2014, 53,6204 .

18 a) E. G. Stanzl, B. M. Trantow, J. R. Vargas and P. A. Wender, Acc. Chem. Res., 2013, 46, 2944. b) S. Futaki, Int. J. Pharm. 2002, 245, 1. 
19 C.-Y. Jiao, D. Delaroche, F. Burlina, I. D. Alves, G. Chassaing and S. Sagan, J. Biol. Chem., 2009, 284, 33957.

20 A. Boulay, A. Seridi, C. Zedde, S. Ladeira, C. Picard, L. Maron and E. Benoist, Eur. J. Inorg. Chem., 2010, 2010, 5058.

21 a) A. j. Di Bilio, B. R. Crane, W. A. Wehbi, C. N. Kiser, M. M. Abu-Omar, R. M. Carlos, J. H. Richards, J. R. Winkler and H. B. Gray, J. Am. Chem. Soc. 2001, 123, 3181. b) A. M. Blanco-Rodríguez, M. Towrie, J. Sýkora, S. Záliš and A. Vlček Jr., Inorg. Chem. 2011, 50, 6122

22 S. T. Henriques and M. A. R. B. Castanho, Biochim. Biophys. Acta BBA - Biomembr., $2005,1669,75$. 